\title{
The correlation between vitamin $D$ deficiency and the severity of painful diabetic neuropathy in patients with type 2 diabetes mellitus (T2DM)
}

\author{
Rizaldy Taslim Pinzon, Putu Clara Shinta Gelgel \\ Faculty of Medicine, Duta Wacana Christian University, Yogyakarta
}

\begin{abstract}
Background: Diabetes and its complications are the major burden health problem worldwide, and diabetic neuropathy is one of the major complications. Vitamin D levels found to be significantly lower in people with painful diabetic peripheral neuropathy compared with healthy people. The data about the vitamin D levels and severity of the neuropathy in Indonesia are very limited. Objective: This study aims to investigate the possible relationship between vitamin D levels and the severity of diabetic peripheral neuropathy. Methods: A cross-sectional study was carried out during the period from October 2019 to December 2019 on 53 subjects with diabetic peripheral neuropathy. The patient's clinical profile including age, gender, and duration of diabetes, HbAlc, and associated microvascular complications was documented. The treatment history was recorded from electronic prescribing data. The severity of neuropathy was measured with the Toronto Clinical Neuropathy Scoring System. Serum 25-OH vitamin D levels were measured by enzyme immunoassays for the quantitative measurement of total serum 25-OH Vitamin D level in ng/mL. Results: Vitamin D levels based on the severity of neuropathy are divided into mild, moderate, and severe. At mild neuropathy severity, the average patient's vitamin D level was $19 \pm 8.85 \mathrm{ng} / \mathrm{mL}$, at moderate severity the patient's vitamin D level was $16.25 \pm 6.08$ $\mathrm{ng} / \mathrm{mL}$, and for severe neuropathy, the average vitamin D level was $13.35 \pm 6.20 \mathrm{ng} / \mathrm{mL}$. Spearman correlation test obtained $r$ value $=$ -0.439 and $p$ value $=0.001$. Conclusions: There is a moderate, significant, and negative patterned correlation between vitamin $D$ level and diabetic peripheral neuropathy severity.
\end{abstract}

KEYWORDS: diabetic peripheral neuropathy severity; type 2 diabetes mellitus; vitamin D

\section{INTRODUCTION}

Diabetes and its complications is the major burden health problem in worldwide and Indonesia $(1,2)$. The data from national health survey in Indonesia showed that the prevalence of diabetes increase $2 \%$ among above 15 years old population (2). Diabetic neuropathy is one of the major complications (2). The prevalence of diabetic peripheral neuropathy in newly diagnosed diabetic patients reaches about $8 \%$. The proportion increase up to $50 \%$ in patients with long-standing disease (3). Among $15 \%$ of all diabetic patients will develop foot ulcer and nontraumatic amputation of lower limbs (4).
The pathogenesis of diabetic peripheral neuropathy is a multifactorial process and multiple hypotheses have been postulated. Previous basic research showed that abnormal expression of sodium and calcium channels, metabolic and autoimmune disorders which lead to glial cell activation contribute to the pathogenesis (5). Recent studies showed that blood vessel changes and activation of central pain mechanisms also played significant role $(5,6)$.

Low vitamin D levels are associated with obesity and insulin resistance (7). Low 25-hydroxyvitamin D levels have been associated with sensory neuropathy in

Korespondensi: Rizaldy Taslim Pinzon, Faculty of Medicine, Duta Wacana Christian University, Jl. Dr. Wahidin Sudirohusodo 5-25, Yogyakarta 55224, Indonesia, e-mail: drpinzon17@gmail.com

How to cite: Pinzon RT, Gelgel PCS. The correlation between vitamin D deficiency and the severity of painful diabetic neuropathy in patients with type 2 diabetes mellitus (T2DM). Jurnal Gizi Klinik Indonesia. 2020;17(1):9-14. doi: 10.22146/ijcn.53924 
diabetes (8). Vitamin D levels also might be correlated with the severity of the neuropathy (9).

The role of vitamin $\mathrm{D}$ in diabetic neuropathy has been studied in previous studies. A recent systematic review showed that vitamin $\mathrm{D}$ deficiency is associated with the generation and development of DPN in Caucasian with type 2 diabetes mellitus (T2DM), and in Asian, diabetic patients with vitamin D deficiency are 1.22 times to suffer from DPN compared with normal vitamin D level (10). A study showed that 25-hydroxyvitamin D levels were significantly lower in people with painful diabetic peripheral neuropathy compared with healthy volunteers and no diabetic peripheral neuropathy patients. Lower 25-hydroxyvitamin D level also correlated with lower cold detection thresholds $(\mathrm{r}=0.39, \mathrm{p}=0.02)$ and subepidermal nerve fibre densities $(r=0.42, p=0.01)(11)$. The data about the vitamin D levels and severity of the neuropathy in Indonesia are very limited. This study aims to investigate the possible relationship between vitamin D levels and the severity of diabetic peripheral neuropathy.

\section{METHODS}

\section{Study design and participants}

A cross sectional study was carried out during the period from October 2019 to December 2019 on 53 subject with diabetic peripheral neuropathy. The study included all patients above the age of 18 years with T2DM with symptoms suggestive of peripheral neuropathy. Patients with neuropathy due to causes other than diabetes and those who refused informed consent were excluded from the study. The sample size was calculated based on estimate of $20 \%$ prevalence of neuropathy in diabetes, allowing for an error of $10 \%$, and thereby a total of 50 patients were recruited. After obtaining approval from the institutional ethical committee (498/E/RSB/2019), patients were recruited in the study based on the inclusion criteria. Informed consent was obtained and the patients were subjected to history and physical examination.

\section{Measures}

In this study, the diagnosis of diabetic peripheral neuropathy based on systematic measurement by a neurologist with Diabetic Neuropathy Symptom and
Diabetic Neuropathy Examination tools (12). The type 2 diabetes mellitus patients were obtained from outpatient neurology clinic of Bethesda Hospital Yogyakarta Indonesia. A standardized instrument was used to record demographic details of the patients. The patient's clinical profile including age, gender, and duration of diabetes, status of glycemic control reflected by $\mathrm{HbA} 1 \mathrm{c}$ and associated microvascular complications were documented. The treatment history was recorded from electronic prescribing data.

The severity of painful diabetic neuropathy. The severity of neuropathy was measured with the Toronto Clinical Neuropathy Scoring System (TCNS) (13). The individual patient's TCNS score was documented out of a total of 19. Severity of neuropathy was classified based on the score as: no neuropathy ( 0 to 5 ), mild neuropathy (6 to 8 ), moderate (9 to 11), and severe diabetic neuropathy (12 to 19).

Vitamin D serum level. The vitamin D level was measured by standardized method in Prodia Research Laboratory. Serum 25-OH vitamin D levels were measured by enzyme immunoassays for the quantitative measurement of total serum 25-OH Vitamin D level in $\mathrm{ng} / \mathrm{mL}$. The level $<10 \mathrm{ng} / \mathrm{mL}$ is deficiency, $10-30 \mathrm{ng} / \mathrm{mL}$ is in-sufficiency, and $30-100 \mathrm{ng} / \mathrm{mL}$ is sufficiency (14).

\section{Data analysis}

Continuous variables were assessed for normality using Shapiro-Wilk's test. If the variables were normally distributed they were expressed as mean \pm standard deviation, otherwise median (interquartile range). Categorical variables were expressed either as percentage or proportions. A comparison of normally distributed continuous variables was done by independent sample t-test, non-normally distributed continuous variables by Mann-Whitney U test, and categorical variables by either Chi-Square test or Fisher's-exact test based on the number of observations. Data analysis and validation was carried out by SPSS. All p-values less than 0.05 were considered statistically significant.

\section{RESULTS}

The study was conducted on 53 T2DM peripheral neuropathy patients, consisting of 11 male patients (20.8\%) and 42 female patients (79.2\%). The mean age of 
observed patients was $57.8 \pm 8.8$ years. Of the 53 patients who participated in the study, 29 patients had T2DM for more than 15 years (54.7\%), 12 patients had T2DM for 10 to 15 years $(22.6 \%)$, and 12 patients had T2DM for less than 10 years $(22.6 \%)$ (Table 1$)$. In this study, vitamin $\mathrm{D}$ levels were measured in all study patients. The mean vitamin D level in male patients was $20.64 \pm 3.96 \mathrm{ng} / \mathrm{mL}$ and in female patients was $14.24 \pm 7.04 \mathrm{ng} / \mathrm{mL}$ (Table 2). The results of measurement of vitamin D level based on the severity of neuropathy are divided into mild, moderate, and severe. At mild neuropathy severity, the average of patient's vitamin D level was $19 \pm 8.85 \mathrm{ng} / \mathrm{mL}$, at the moderate severity the patient's vitamin D level was $16.25 \pm 6.08 \mathrm{ng} / \mathrm{mL}$, and for severe neuropathy, the average vitamin D level was $13.35 \pm 6.20 \mathrm{ng} / \mathrm{mL}$ (Table 3). Correlation analysis in Table 3 shows the correlation between vitamin D level and neuropathy severity and the result shows that decreasing vitamin $\mathrm{D}$ level correlates with increased neuropathy severity $(r=-0.439 ; \mathrm{p}=0.001)$.

There was a statistically significant relationship between gender, hypertension, and status of glycemic control as factors that affect patients' vitamin D levels $(p<0.05)$. Confounding variables such as duration of DM, history of cardiovascular disease, oral antidiabetic medication, and insulin therapy did not show a significant relationship with the patient's vitamin $\mathrm{D}$ level $(\mathrm{p}>0.05)$.

\section{DISCUSSION}

The data showed that only one study subject had sufficient vitamin D levels. The proportion of subjects with a deficiency was 12/53 (22.6\%). Most of the study subjects had insufficient vitamin D levels (75.4\%). This result is consistent with some previous studies. The study from Bayani, from 120 T2DM patients showed that vitamin D level was deficient in 77 (64.2\%), insufficient in $30(25 \%)$, and sufficient in $13(10.3 \%)$ patients (15). A large epidemiological study showed that the overall prevalence of patients with low vitamin D levels (vitamin D deficiency and insufficiency) was 1257 (83.7\%); and $1231(82 \%)$ were newly diagnosed cases. Out of 1257 (83.7\%) patients with low vitamin D levels, $60.9 \%$ of patients had vitamin D deficiency, and $22.9 \%$ of patients had vitamin D insufficiency (16).
Table 1. Baseline characteristic

\begin{tabular}{|c|c|c|}
\hline Characterisctic & $\mathrm{n}=\mathbf{5 3}$ & $\%$ \\
\hline \multicolumn{3}{|l|}{ Gender } \\
\hline Male & 11 & 20.8 \\
\hline Female & 42 & 79.2 \\
\hline \multicolumn{3}{|l|}{ Age (years) } \\
\hline$<60$ & 33 & 62.3 \\
\hline$\geq 60$ & 20 & 37.7 \\
\hline \multicolumn{3}{|l|}{ Duration of DM (years) } \\
\hline$<10$ & 29 & 54.7 \\
\hline $10-15$ & 12 & 22.6 \\
\hline$>15$ & 12 & 22.6 \\
\hline \multicolumn{3}{|l|}{ Hypertension } \\
\hline Yes & 26 & 49.1 \\
\hline No & 27 & 50.9 \\
\hline \multicolumn{3}{|l|}{ Cardiovascular disease } \\
\hline Yes & 13 & 24.5 \\
\hline No & 40 & 75.5 \\
\hline \multicolumn{3}{|l|}{ Vitamin D level (ng/mL) } \\
\hline Deficiency (10) & 12 & 22.6 \\
\hline Insufficiency (10-30) & 40 & 75.5 \\
\hline Suficiency $(30-100)$ & 1 & 1.9 \\
\hline Toxicity $(>100)$ & 0 & 0 \\
\hline \multicolumn{3}{|c|}{ Oral antidiabetic medication } \\
\hline Yes & 50 & 94.3 \\
\hline No & 3 & 5.7 \\
\hline \multicolumn{3}{|l|}{ Insulin } \\
\hline Yes & 20 & 37.7 \\
\hline No & 33 & 62.3 \\
\hline \multicolumn{3}{|l|}{ Status of glycemic control } \\
\hline Controlled & 35 & 66.0 \\
\hline Uncontrolled & 18 & 34.0 \\
\hline
\end{tabular}

This study showed that patients with severe neuropathy are correlated with low vitamin D status. Some previous studies showed a similar result. The study from 60 patients with diabetes (thirty with neuropathy and thirty without neuropathy) showed that vitamin D levels were significantly decreased in diabetic patients and those with neuropathy when compared to those without neuropathy $(\mathrm{p}<0.05)$. Vitamin D levels were significantly reduced with increasing severity of neuropathy $(\mathrm{p}=0.001)$ (17). Another study conducted by Ahmadieh reported that the prevalence of diabetic neuropathy increases with a decrease in 25-OH vitamin $\mathrm{D}$ level. The percentage of neuropathy increased in patients with $25-\mathrm{OH}$ vitamin $\mathrm{D}$ level below $20 \mathrm{ng} / \mathrm{mL}$ (18).

There is emerging evidence that vitamin D is a neurotrophic substance, but its role in diabetic neuropathic pain needs further studies (19). Some 
Table 2. The vitamin D level comparison based on the characteristic of the subjects

\begin{tabular}{|c|c|c|c|}
\hline Characterisctic & $\begin{array}{c}\text { Mean } \\
\text { vitamin D } \\
\text { level }(\mathrm{ng} / \mathrm{mL})\end{array}$ & $\begin{array}{c}\text { SD } \\
\text { vitamin D } \\
\text { level }(\mathrm{ng} / \mathrm{mL})\end{array}$ & $\mathbf{p}$ \\
\hline \multicolumn{4}{|l|}{ Gender } \\
\hline Male & 20.64 & 3.96 & 0.003 \\
\hline Female & 14.24 & 7.04 & \\
\hline \multicolumn{4}{|l|}{$\begin{array}{l}\text { Duration of DM } \\
\text { (years) }\end{array}$} \\
\hline$<10$ & 16.17 & 7.61 & \\
\hline $10-15$ & 17.67 & 5.35 & 0.105 \\
\hline$>15$ & 12.00 & 5.98 & \\
\hline \multicolumn{4}{|l|}{ Hypertension } \\
\hline Yes & 17.73 & 7.49 & 0.030 \\
\hline No & 13.48 & 5.91 & \\
\hline \multicolumn{4}{|l|}{$\begin{array}{l}\text { Cardiovascular } \\
\text { disease }\end{array}$} \\
\hline Yes & 15.69 & 6.63 & 0.844 \\
\hline No & 15.53 & 7.20 & \\
\hline \multicolumn{4}{|l|}{$\begin{array}{l}\text { Oral antidiabetic } \\
\text { medication }\end{array}$} \\
\hline Yes & 15.68 & 7.18 & 0.729 \\
\hline No & 13.67 & 2.08 & \\
\hline \multicolumn{4}{|l|}{ Insulin } \\
\hline Yes & 15.45 & 6.03 & 0.876 \\
\hline No & 15.64 & 7.62 & \\
\hline \multicolumn{4}{|l|}{$\begin{array}{l}\text { Status of glycemic } \\
\text { control }\end{array}$} \\
\hline Controlled & 17.54 & 6.89 & 0.004 \\
\hline Uncontrolled & 11.72 & 5.59 & \\
\hline
\end{tabular}

Table 3. The vitamin D level based on the severity of neuropathy

\begin{tabular}{lccc}
\hline \multirow{2}{*}{\multicolumn{1}{c}{ Vitamin D }} & \multicolumn{3}{c}{ Severity of neuropathy } \\
\cline { 2 - 4 } & Mild & Moderate & Severe \\
\hline Mean $(\mathrm{ng} / \mathrm{mL})$ & 19.00 & 16.26 & 13.35 \\
Standard deviation (ng/mL) & 8.85 & 6.08 & 6.20 \\
Significance & \multicolumn{3}{c}{0.001} \\
\hline
\end{tabular}

researcher hypothesized that vitamin D deficiency may potentiate diabetic nerve damage and may impair nociceptor function, resulting in pain at a threshold of serum $25(\mathrm{OH})$ vitamin $\mathrm{D}$ higher than that in the nondiabetic population (20).

The next important question is "should we add vitamin $\mathrm{D}$ treatment in patients with painful diabetic neuropathy". A quasi-experimental trial sixty type 2 DM subjects (30-65 years old) with painful diabetic neuropathy was performed. Patients received weekly 50000 IU of vitamin D3 for 12 weeks orally. Among 60 T2DM patients, 58 completed the study. At the end of study, $\mathrm{HbAlc}$, vitamin D, and patient's clinical condition assessed by Michigan Neuropathy Screening Instrument (MNSI) (both questionnaire and physical examination) improved significantly (p-value $<0.001$ ). Oral supplementation of vitamin D (50000 IU) once a week for 12 weeks was associated with a significant decrease in the symptoms and signs of diabetic neuropathy (21). Lee and Chen showed that vitamin D supplementation over 3 months improved neuropathic symptoms by $50 \%$ in diabetic patients with vitamin D deficiency at baseline (22).

The mean vitamin $\mathrm{D}$ level in male patients in this study was $20.64 \pm 3.96 \mathrm{ng} / \mathrm{mL}$, and female patients were $14.24 \pm 7.04 \mathrm{ng} / \mathrm{mL}$. Gender was found to have a statistically significant effect on vitamin D levels. In previous studies, it was stated that gender affected vitamin D status, in which $25(\mathrm{OH}) \mathrm{D}$ level of women were lower than men and played a role in determining the severity of coronary artery disease (23). The duration of T2DM patients in this study were divided into less than 10 years, $10-15$ years and more than 15 years. The duration of DM was found to be statistically insignificant due to vitamin D level. Based on theory that the severity of DM associated with prolonged hyperglycemia that can cause nerve damage and exacerbate neuropathy symptoms (24).

Hypertension in this study was significantly related to vitamin D level. Another study also found that every $10 \%$ increase in plasma $25(\mathrm{OH}) \mathrm{D}$ level was associated with a decrease in diastolic and systolic blood pressure and $8.1 \%$ decreased hypertension $(\mathrm{OR}=0.92,95 \% \mathrm{CI}$ : $0.87-0.97 ; \mathrm{p}=0.002$ ) (25). In this study, the history of cardiovascular disease did not significantly influence vitamin $\mathrm{D}$ level. Maintaining optimal vitamin $\mathrm{D}$ level is important not only for maintaining calcium homeostasis but also for the risk of cardiovascular disease and blood pressure control. Vitamin D has an effect on the cardiovascular system by reducing the activity of the renin angiotensin-aldosterone system, decreases blood pressure, and has anti-inflammatory and antithrombotic effect (26).

Oral antidiabetic medication and insulin therapy do not significantly influence vitamin $\mathrm{D}$ level. The status 
of glycemic control reflected by HbA1c is significantly related to vitamin D level. The same thing also found in another study that there is a significant relationship in the vitamin D supplementation to decrease HbA1c $(7.9 \pm 1.7 \%$ vs $7.4 \pm 1.2 \%, \mathrm{p}=0.001$ ) (27).

The study has some limitations. It was a hospitalbased study and hence the results may not be generalized to the population on a community basis. The authors could not find enough subjects with normal vitamin D status. We also did not compare the vitamin D level in patients without neuropathy. As a preliminary study on the correlation of vitamin D with neuropathy in Indonesia, further studies and clinical trials are warranted.

\section{CONCLUSIONS}

There is a moderate, significant, and negative patterned correlation between vitamin D level and diabetic peripheral neuropathy severity.

\section{Declaration of conflicting interests}

The authors declare that there is no conflict of interests regarding the publication of this paper.

\section{REFERENCES}

1. Boulton A, Malik R, Arezzo J, Sosenko J. Diabetic somatic neuropathies. Diabetes Care. 2004;27(6):1458-86. doi: 10.2337/diacare.27.6.1458

2. National Institute of Health and Research Development (Balitbangkes). Laporan nasional Riskesdas 2018. [series online] 2019 [cited September 27 2019]. Available from: URL: http://labdata.litbang.kemkes.go.id/images/ download/laporan/RKD/2018/Laporan_Nasional_ RKD2018_FINAL.pdf

3. Dang C, Boulton A. Changing perspectives in diabetic foot ulcer management. Int J Low Extrem Wounds. 2003;2(1):4-12. doi: 10.1177/1534734603002001002

4. Tesfaye S, Boulton A, Dyck P, Freeman R, Horowitz M, Kempler P, et al. Diabetic neuropathies: update on definitions, diagnostic criteria, estimation of severity, and treatments. Diabetes Care. 2010;33(10):2285-93. doi: $10.2337 / \mathrm{dc} 10-1303$

5. Tahrani A, Ball A, Shepherd L, Rahim A, Jones A, Bates A. The prevalence of vitamin D abnormalities in South Asians with type 2 diabetes mellitus in the UK. Int J Clin Pract. 2010;64(3):351-5. doi: 10.1111/j.1742-1241.2009.02221.x
6. Usluogullari C, Balkan F, Caner S, Ucler R, Kaya C, Ersoy R, et al. The relationship between microvascular complications and vitamin D deficiency in type 2 diabetes mellitus. BMC Endocr Disord. 2015;15:33. doi: 10.1186/ s12902-015-0029-y

7. Lee J, Oh S, Ha W, Kwon H, Sohn T, Cha B, et al. Serum 25-hydroxyvitamin D concentration and arterial stiffness among type 2 diabetes. Diabetes Res Clin Pract. 2012;95(1):42-7. doi: 10.1016/j.diabres.2011.09.006

8. Al-Timimi DJ, Ali AF. Serum 25(OH) D in diabetes mellitus type 2: relation to glycaemic control. J Clin Diagn Res. 2013;7(12):2686-8. doi: 10.7860/JCDR/2013/6712.3733

9. Olt S. Relationship between vitamin D and glycemic control in patients with type 2 diabetes mellitus. Int J Clin Exp Med. 2015;8(10):19180-3.

10. Qu GB, Wang LL, Tang X, Wu W, Sun YH. The association between vitamin $\mathrm{D}$ level and diabetic peripheral neuropathy in patients with type 2 diabetes mellitus: an update systematic review and meta-analysis. J Clin Trans1 Endocrinol. 2017;9:25-31. doi: 10.1016/j.jcte.2017.04.001

11. Shillo P, Selvarajah D, Greig M, Ghandi R, Rao G, Tesfaye $\mathrm{S}$, et al. Reduced vitamin $\mathrm{D}$ level in painful diabetic peripheral neuropathy. Diabet Med. 2019,36(1):44-51. doi: 10.1111/dme.13798

12. Maijer JWG, Bosma E, Lefrandt JD, Links TP, Smit AJ, Hoogenberg K, et al. Clinical diagnosis of diabetic polyneuropathy with the diabetic neuropathy symptom and diabetic neuropathy examination scores. Diabetes Care. 2003;26(3):697-701. 10.2337/diacare.26.3.697

13. Bril V, Perkins B. Validation of the Toronto clinical scoring system for diabetic polyneuropathy. Diabetes Care. 2002;25(11):2048-52. doi: 10.2337/diacare.25.11.2048

14. Arneson WL, Arneson DL. Current methods for routine clinical laboratory testing of vitamin D levels. Laboratory Medicine. 2013;44(1):e38-42. doi: 10.1309/ LMONQZQ27TIN7XFS

15. Bayani MA, Akbari R, Banasaz B, Saeedi F. Status of vitamin-D in diabetic patients. Caspian J Intern Med. 2014;5(1):40-2.

16. Talwalkar PG, Deshmukh V, Deepak MC, Agrawal D, Patel I, Hegde R. Prevalence and clinico-epidemiology of vitamin $\mathrm{D}$ deficiency in patients with type 2 diabetes mellitus and hypertension - a Pan-India study. Endocrine Abstracts. 2018;56:P218. doi: 10.1530/endoabs.56.P218

17. IWA Dalia, MA Abdelmula, Zeinab AE, AbdElkarim AA. Association of vitamin D with diabetic neuropathy among Sudanese patients with type 2 diabetes mellitus. Niger J Basic Clin Sci. 2019;16(2):79-82. doi: 10.4103/ njbcs.njbcs_8_19

18. Ahmadieh $\mathrm{H}, \mathrm{Azar} \mathrm{S}$, Lakkis N, Arabi A. Hypovitaminosis $\mathrm{D}$ in patients with type 2 diabetes mellitus: a relation 
to disease control and complications. ISRN Endocrinol 2013;2013:641098. doi: 10.1155/2013/641098

19. Shehab D, Al-Jarallah K, Mojiminiyi OA, Al Mohamedy $\mathrm{H}$, Abdella NA. Does vitamin D deficiency play a role in peripheral neuropathy in type 2 diabetes? Diabet Med. 2012;29(1):43-9. doi: 10.1111/j.1464-5491.2011.03510.x

20. Bilir B, Tulubas F, Bilir B, Atile N, Kara S, Yildirim $\mathrm{T}$, et al. The association of vitamin $\mathrm{D}$ with inflammatory cytokines in diabetic peripheral neuropathy. J Phys Ther Sci. 2016;28(7):2159-63. doi: 10.1589/jpts.28.2159

21. Ghadiri-Anari A, Mozafari Z, Gholami S, Khodaei SA, Aboutorabi-Zarchi M, Namiranian N, et al. Dose vitamin D supplementations improve peripheral diabetic neuropathy? a before-after clinical trial. Diabetes Metab Syndr. 2019;3(1):890-3. doi: 10.1016/j.dsx.2018.12.014

22. Lee $P, C$ hen R. Vitamin D as an analgesic for patients with type 2 diabetes and neuropathic pain. Arch Intern Med. 2008;168(7):771-2. doi: 10.1001/archinte.168.7.771
23. Verdoia M, Schaffer A, Barbieri L, Di Giovine G, Marino P, De Luca G, et al. Impact of gender difference on vitamin D status and its relationship with the extent of coronary artery disease. Nutr Metab Cardiovasc Dis. 2015;25(5):464-70. doi: 10.1016/j.numecd.2015.01.009

24. Sudoyo AW, Setiyohadi B, Alwi I. Buku ajar ilmu penyakit dalam; Jilid III, Edisi V. Jakarta: Interna Publishing; 2009.

25. Afzal S, Nordestgaard BG. Low vitamin D and hypertension: a causal association?. Lancet Diabetes Endocrinol. 2014;2(9):682-4. doi: 10.1016/S2213-8587(14)70119-6

26. Mozos I, Marginean O. Links between vitamin D deficiency and cardiovascular diseases. Biomed Res Int. 2015;2015:109275. doi: 10.1155/2015/109275

27. Nada AM, Shaheen DA. Cholecalciferol improves glycemic control in type 2 diabetic patients: a 6-month prospective interventional study. Ther Clin Risk Manag. 2017;13:813-20. doi: 10.2147/TCRM.S132344 